07,13

\title{
Влияние толщины бислоя наноструктурного многослойного покрытия MoN/CrN на его микроструктуру, твердость и элементный состав
}

\author{
(C) А.Д. Погребняк ${ }^{1}$, О.В. Бондар ${ }^{1,2}$, Б. Жоллыбеков ${ }^{3}$, С. Константинов ${ }^{4}$, P. Konarski ${ }^{5}$, \\ В.М. Береснев ${ }^{6}$, А.И. Купчишин \\ ${ }^{1}$ Сумский государственный университет, \\ Сумы, Украина \\ ${ }^{2}$ NanoBioMedical Centre, Adam Mickiewicz University, \\ Poznan, Poland \\ ${ }^{3}$ Каракалпакский государственный университет им. Бердаха, \\ Нукус, Узбекистан \\ ${ }^{4}$ Белорусский государственный университет, \\ Минск, Беларусь \\ ${ }^{5}$ Tele and Radio Research Institute, \\ Warsaw, Poland \\ ${ }^{6}$ Харьковский национальный университет им. В.Н. Каразина, \\ Харьков, Украина \\ ${ }^{7}$ Казахский национальный педагогический университет, \\ Алматы, Казахстан \\ E-mail: alexp@i.ua
}

(Поступила в Редакцию 28 апреля 2016 г.

В окончательной редакции 14 марта 2017 г.)

Многослойные наноструктурные покрытия, состоящие из чередующихся слоев $\mathrm{MoN}$ и $\mathrm{CrN}$, получены методом вакуумно-дугового испарения катода при различных условиях осаждения. Переход от микронных размеров бислоев к нанометровому масштабу в исследуемых покрытиях приводит к росту нанотвердости от 15 до $35.5 \mathrm{GPa}$ (при толщине слоя порядка $35 \mathrm{~nm}$ ). В то же время с уменьшением количества бислоев в покрытии среднее значение твердости по Виккерсу увеличивается от $1267 \mathrm{HV}_{0.05}$ до $3307 \mathrm{HV}_{0.05}$. Повышение величины подаваемого на подложку потенциала от -20 до $-150 \mathrm{~V}$ приводит к формированию в слоях покрытий текстуры роста с осью [100], а также к увеличению интенсивности рефлексов с ростом толщины бислоев. Элементный анализ, проведенный с помощью резерфордовского обратного рассеяния, вторичной ионной масс-спектрометрии и энергодисперсионных спектров, показал хорошее разделение слоев MoN и $\mathrm{CrN}$ вблизи поверхности покрытий.

Работа выполнена в рамках бюджетных тематик № 0115U000682 „Разработка материаловедческих основ структурной инженерии вакуумно-плазменных сверхтвердых покрытий с целью достижения необходимых функциональных свойств“ и № 0116U006816 „Разработка перспективных наноструктурных многослойных покрытий с улучшенными физико-механическими и трибологическими свойствами“.

DOI: $10.21883 /$ FTT.2017.09.44850.163

\section{1. Введение}

Вакуумно-дуговые покрытия на основе нитридов переходных металлов обладают высокой твердостью и хорошей адгезией к подложке [1-4]. При переходе нитридных покрытий в наноструктурное состояние [5] отмечается существенное улучшение их физико-механических и трибологических свойств, повышение стойкости к температурным воздействиям [6-9], улучшение коррозионной стойкости [10-14] и т.д. Одним из способов реализации перехода покрытий в наноструктурное состояние является осаждение многослойных композиционных материалов [15-17], в которых чередование слоев из разных составляющих [14,18] служит хорошим диффузионным барьером [19] и обеспечивает повышение стабильности свойств при внешних воздействиях [20]. В этом случае сверхтвердое состояние многослойных нанокомпозитов предполагает подавление процессов роста зародышевых трещин, генерирования и распространения дислокаций, обеспечивающих пластический сброс деформации при уменьшении размеров нанокристаллитов до $10 \mathrm{~nm}$ [21], и отсутствие характерной для наноструктурных материалов аномальной зависимости Холла-Петча [22].

В качестве одних из наиболее перспективных многослойных систем в последнее время рассматриваются системы на основе нитридов или карбидов тугоплавких металлов, такие как MoN/CrN [22], поскольку указанные композиции позволяют достичь высокой твердости и износостойкости покрытия в сочетании с хорошей устойчивостью к окислению и прочим воздействиям в агрессивной среде [23].

Настоящая работа посвящена изучению влияния толщины бислоев и параметров осаждения на фазовый состав, микроструктуру и твердость покрытий, осажден- 
ных при различной величине отрицательного потенциала смещения $U_{b}$, подаваемого на подложку, обеспечивающего увеличение энергии осаждаемых частиц.

\section{2. Методы получения покрытий и их исследования}

Покрытия осаждались на стальные подложки при помощи вакуумно-дугового испарения катода на установке Булат 6-М [20]. Давление рабочей атмосферы (азота) в камере было практически постоянным $\left(P_{\mathrm{N}}=3 \cdot 10^{-3}\right.$ Torr $)$, скорость осаждения составляла около $3 \mathrm{~nm} / \mathrm{s}$. Осаждение проводилось с двух мишеней: катодов из молибдена и хрома - при фиксированном времени выдержки и непрерывном вращении закрепленных образцов со скоростью $8 \mathrm{rpm}$. Общая толщина покрытий составила примерно $10 \mu \mathrm{m}$, длительность осаждения около часа. В процессе осаждения покрытий на подложки из нержавеющей стали подавался постоянный отрицательный потенциал $U_{b}=-20$ и $-150 \mathrm{~V}$. Структурно-фазовый анализ проводился методом рентгеновской дифрактометрии (XRD) в излучении $\mathrm{Cu} K_{\alpha}$ на установке X'Pert PANanalytical с шагом $0.05^{\circ}$ (в диапазоне углов $\left.2 \theta=30-80^{\circ}\right)$. Разделение профилей на составляющие фрагменты осуществлялось с использованием программного обеспечения Powder Cell. Элементный анализ и исследование сечений покрытий проводились несколькими методами растровой электронной микроскопии (SEM) с микроанализом на микроскопе JEM-7001 TTLS (JEOL) в режимах SEI и COMPO. Образцы с покрытиями разрезались алмазным диском на приборе Buehler IsoMet Lowspeed Saw, затем часть покрытия на срезе вытравливалась с помощью фокусированного ионного пучка (ионы галлия) JEOL JIB4000 Focused Ion Beam System. Для анализа профилей распределения элементов по глубине покрытия использовался поток ионов $\mathrm{He}^{+}$с энергией $1.4 \mathrm{MeV}$ в геометрии резерфордовского обратного рассеяния ионов (RBS) с энергетическим разрешением детектора $16 \mathrm{keV}$. Для расчета профилей элементов в покрытии использовалось программное обеспечение RESOLNRA.

Для элементного анализа также использовался метод вторичной ионной масс-спектрометрии (SIMS). Исследования проводились на установке SAJW 05, оборудованной аргонной ионной пушкой Physical Electronics и квадрупольным масс-анализатором QMA 410 Balzers. Перед началом исследований проводилась предварительная регистрация спектров масс с целью калибровки установки. Размеры вытравленного кратера составляли $2.5 \times 2.5 \mathrm{~mm}$, энергия пучка ионов задавалась равной $1.72 \mathrm{keV}$, ток $-0.3 \cdot 10^{-6} \mathrm{~A}$, при этом средняя скорость распыления составляла примерно $0.65 \mathrm{~nm} / \mathrm{min}$. Вторичные ионы регистрировались только в центральной части кратера, площадь которой составляла лишь 15\% от общей площади кратера. Достаточно низкие значения энергии пучка позволили избавиться от эффекта смешивания ионов, возникающего во время распыления материала покрытия.

Измерения твердости проводились на приборе ДМ-8 с использованием пирамидки Виккерса, нагрузка на которую составляла 500 и $100 \mathrm{~g}$.

\section{3. Результаты и их обсуждение}

Энергодисперсионный анализ элементного состава покрытий показал, что для покрытий всех серий, полученных как при низком $U_{b}=-20 \mathrm{~V}$, так и высоком $U_{b}=-150 \mathrm{~V}$, состав по металлическим компонентам близок к эквиатомному, причем атомное отношение $\mathrm{Mo} / \mathrm{Cr}$ изменяется от 0.90 до 0.93. Следовательно, можно утверждать, что толщины получаемых слоев будут практически равными. При изменении $U_{b}$ от -20 до $-150 \mathrm{~V}$ содержание атомов азота практически не изменяется. XRD-исследования показывают, что величина $U_{b}$ в значительной мере влияет на формируемое
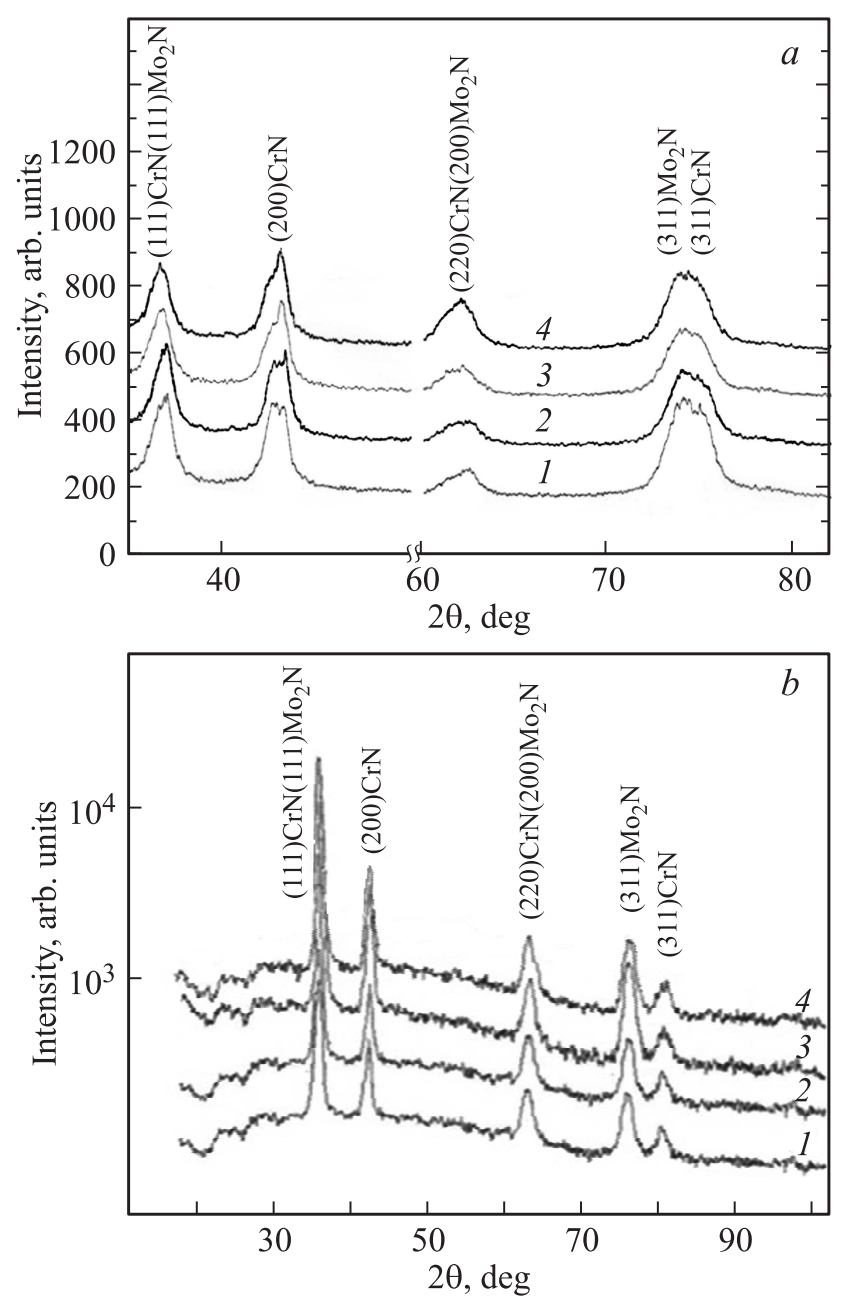

Рис. 1. Участки дифракционных спектров покрытий, полученных при $U_{b}=-20(a)$ и $-150 \mathrm{~V}(b)$ при толщине слоев $h=300$ (1), 70 (2), 20 (3), $12 \mathrm{~nm}(4)$. 
структурное состояние. Из сравнения рис. $1, a$ и $b$ видно, что при небольшом потенциале $U_{b}=-20 \mathrm{~V}$ в покрытиях формируется одинаковый тип кристаллических решеток: кристаллические решетки структурного типа $B 1$ (ГЦК типа $\mathrm{NaCl}$ ), что характерно для $\mathrm{CrN}$ и $\gamma-\mathrm{Mo}_{2} \mathrm{~N}$. В процессе исследований была обнаружена преимущественная ориентация роста кристаллитов с осью [311], перпендикулярной плоскости роста, что проявляется в относительном усилении интенсивности соответствующего рефлекса. Однако в слоях $\mathrm{CrN}$ такой тип текстуры является более выраженным. Подача на подложку большего потенциала смещения $U_{b}=-150 \mathrm{~V}$ формирует другой тип текстуры [111], которая улучшается с ростом толщины слоя, однако не приводит к явному разделению рефлексов от соответствующих фаз двух нитридных слоев при больших углах дифракции, что свидетельствует об образовании твердого раствора.

При подаче потенциала $U_{b}=-150 \mathrm{~V}$ происходит рост поликристаллического нетекстурированного состояния. При этом в осажденных слоях происходит формирование мононитрида хрома $\mathrm{CrN}$ и $\gamma-\mathrm{Mo}_{2} \mathrm{~N}$ с кубической решеткой типа $\mathrm{NaCl}$. Появление текстур такого типа обусловлено относительным уменьшением содержания азота в покрытии с ростом величины потенциала смещения, подаваемого на подложку. Наличие структур с совпадающими межплоскостными расстояниями в контактирующих слоях свидетельствует о взаимосвязанном росте этих двух структур.

На субструктурном уровне размеры нанокристаллитов в случае осаждения наноразмерных слоев составляют $L=12 \mathrm{~nm}$, а микродеформация кристаллитов равна $\langle\varepsilon\rangle \approx 0.4-0.5 \%$. Полученные значения микродеформации несколько выше в покрытиях, осажденных при подаче низкого потенциала смещения на подложку, чем в покрытиях, полученных при подаче более высоких потенциалов смещения на подложку. Данный факт объясняется меньшей подвижностью осаждаемых атомов, приводящей к уменьшению вероятности диффузионного залечивания дефектов роста. Разделения рефлексов от соответствующих фаз двух слоев не наблюдается, что дополнительно свидетельствует об образовании твердого раствора.

SEM-изображение сечения многослойного покрытия (44 слоя, общая толщина покрытия порядка $7 \mu \mathrm{m})$ приведена на рис. 2. Слои хорошо разрешаются с помощью сканирующего электронного микроскопа, обладают отчетливо различимыми границами.

Образцы с покрытием MoN/CrN (180 слоев) исследовались при помощи резерфордовского обратного рассеяния ионов $\mathrm{He}^{+}$. Было установлено, что пучок пронизывает одиннадцать бислоев. Толщины слоев $\mathrm{CrN}$ и $\mathrm{MoN}$ во всех периодах равны 86 и $75 \mathrm{~nm}$ соответственно, что дает толщину бислоя, равную $151 \mathrm{~nm}$. На рис. 3 представлены профили распределения элементов $\mathrm{Cr}$, Мо, $\mathrm{N}$ по глубине (на глубину до $1800 \mathrm{~nm}$ ), которые не смешиваются в процессе осаждения, по крайней мере на глубину анализа ионного пучка.

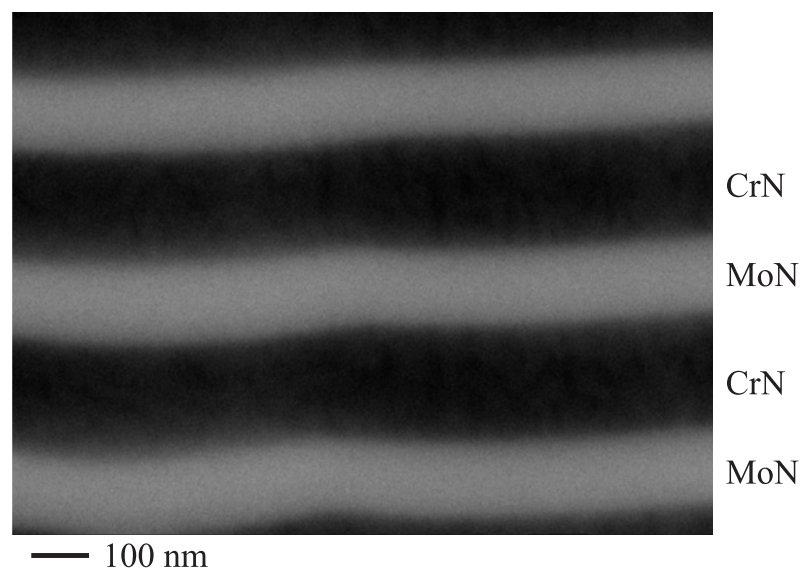

Рис. 2. SЕМ-снимок бокового сечения покрытия, соответствующего дифракционному спектру 1 на рис. $1, b$, полученный с увеличением 100000 раз.

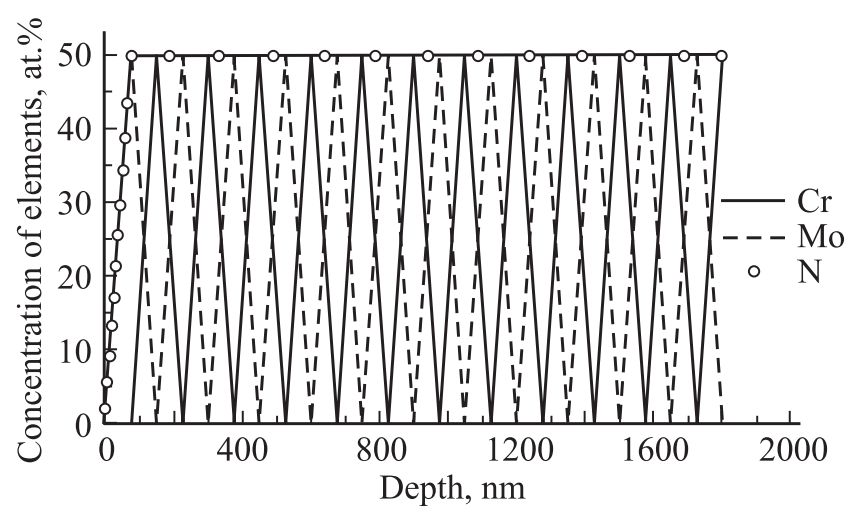

Рис. 3. Профили распределения элементов по глубине покрытия, полученные из спектров RBS ионов $\mathrm{He}^{+}$, на образцах с покрытиями $\mathrm{MoN} / \mathrm{CrN}$ (180 слоев).

В то же время результаты SIMS-исследований, представленные на рис. 4, дополняют данные RBS и также свидетельствуют о хорошем качестве осажденных покрытий. Из-за различных скоростей распыления слоев $\mathrm{CrN}$ и $\mathrm{MoN}$ наблюдается несколько заниженная толщина слоев. Поэтому при помощи нормировки результатов SIMS на результаты RBS-анализа, а именно на толщину слоев, полученных методом RBS с точностью до $0.1 \mathrm{~nm}$, мы получаем более реальные значения в профилях концентраций азота в исследуемых слоях уже из результатов SIMS. Из профилей элементов, представленных на рис. 4, хорошо видно, что слои нитрида хрома имеют более высокую концентрацию азота, чем слои нитрида молибдена, о чем свидетельствует увеличение интенсивности пиков азота, совпадающих с положениями пиков хрома. Полученные результаты хорошо согласуются с данными XRD-исследований.

Результаты исследования твердости таких покрытий, представленные на рис. 5, показали, что при низком $U_{b}=-20 \mathrm{~V}$ при уменьшении толщины слоев наблюдается повышение твердости многослойного композита. Это 


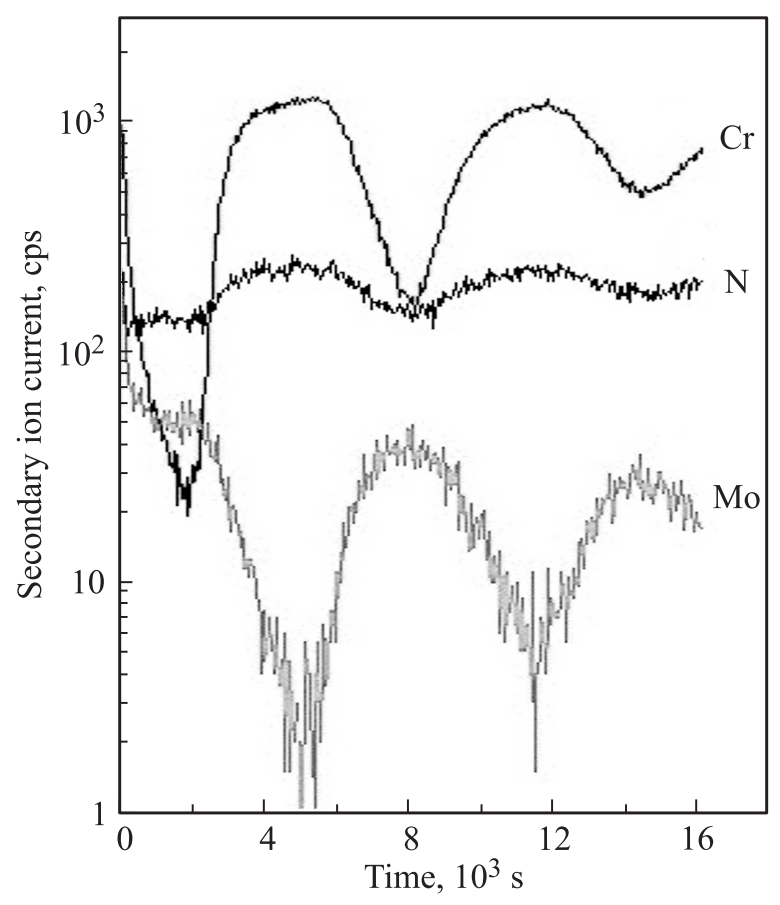

Pис. 4. Результаты SIMS-исследований покрытия MoN/CrN (180 слоев): первые четыре слоя в увеличенном масштабе.

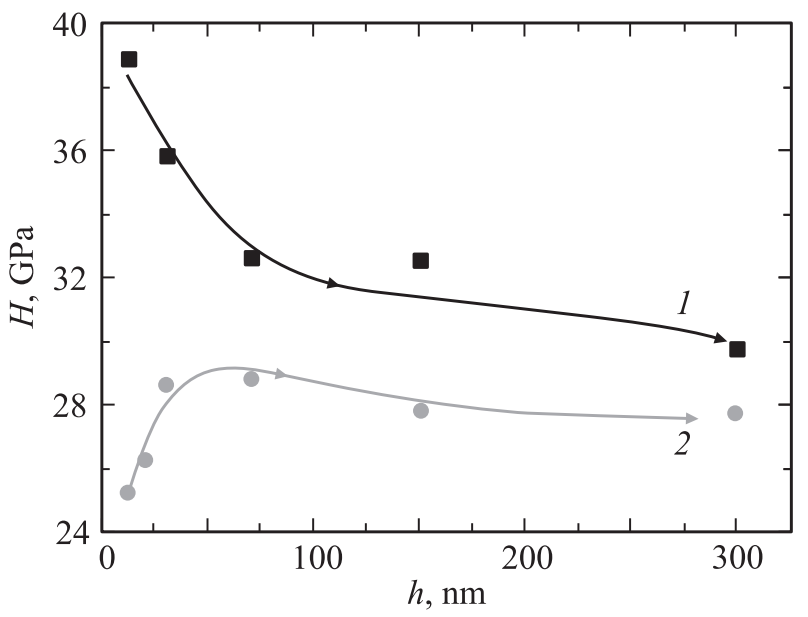

Рис. 5. Зависимость микротвердости $H$ от толщины слоя $h$ для покрытий, полученных при $U_{b}=-20$ (1) и $-150 \mathrm{~V}$ (2). Погрешности измерений указаны в качестве доверительных интервалов.

может быть связано с характерными эффектами уменьшения размера зерен (уравнение Холла-Петча) [22]. При большем потенциале смещения $U_{b}=-150 \mathrm{~V}$ такая тенденция сохраняется до толщин слоев около $40 \mathrm{~nm}$, в то время как при меньших толщинах наблюдается падение твердости, что может быть объяснено большим числом границ и увеличением их объемной доли в покрытии. Причиной такого падения является потеря межфазной границей барьерных свойств из-за образования твердого раствора $(\mathrm{Mo}, \mathrm{Cr}) \mathrm{N}$ за счет перемешивания высокоэнергетических частиц (потенциал смещения
$\left.U_{b}=-150 \mathrm{~V}\right)$ на границах отдельных слоев. Наибольшая твердость покрытий достигается при наличии в слоях $\mathrm{Cr}-\mathrm{N}$ фазы $\mathrm{CrN}$ с кубической решеткой и сравнительно малой областью гомогенности по составу. Максимальные значения твердости (до $35.5 \mathrm{GPa}$ ) наблюдаются в покрытиях, в которых соотношение $\mathrm{Mo} / \mathrm{Cr}$ равно 0.9 .

\section{4. Заключение}

Проведены фазовый и элементный анализ микро- и наноструктурных многослойных покрытий на основе $\mathrm{MoN} / \mathrm{CrN}$, а также исследована их твердость в зависимости от различных режимов осаждения. В результате изменения подаваемого на подложку потенциала смещения от -20 до $-150 \mathrm{~V}$, а также увеличения толщины бислоев от 24 до $300 \mathrm{~nm}$ в покрытиях были получены разные структуры: от кубической (типа $\mathrm{NaCl}$ ) до образования твердого раствора. Такие условия осаждения существенно повлияли и на изменение структуры роста многослойных покрытий. При получении фаз $\mathrm{CrN}$ и $\gamma-\mathrm{Mo}_{2} \mathrm{~N}$ с кубической решеткой в покрытиях фиксировалась наибольшая твердость: $35.5 \mathrm{GPa}$. Совпадение межплоскостных расстояний в контактирующих слоях нитридов хрома и молибдена свидетельствует о взаимосвязанном росте этих двух структур.

Авторы признательны Ф.Ф. Комарову (Белорусский государственный университет, Минск) за помощь в измерении RBS-спектров, B. Peplinska и Е. Coy (NanoBioMedical Centre, Adam Mickiewicz University, Poznan, Poland) за помощь в измерении структуры покрытий с помощью SEM и О.В. Соболю за помощь в интерпретации спектров XRD.

\section{Список литературы}

[1] Nanostructured coatings / Eds A. Cavaleiro, J.T.M. De Hosson. Springer, N.Y. (2006). 648 p.

[2] R.L. Boxman, V.N. Zhitomirsky, I. Grimberg, L. Rapoport, S. Goldsmith, B.Z. Weiss. Surf. Coat. Technol. 125, 257 (2000).

[3] P.H. Mayrhofer, C. Mitterer, L. Hultman, H. Clemens. Prog. Mater. Sci. 51, 1032 (2006).

[4] А.Д. Погребняк, А.П. Шпак, Н.А. Азаренков, В.М. Береснев. УФН 179, 1, 3 (2009).

[5] А.Д. Погребняк, А.Г. Пономарев, А.П. Шпак, Ю.А. Куницкий. УФН 182, 3, 287 (2012).

[6] T.N. Koltunowicz, P. Zukowski, V. Bondariev, K. Czarnacka, O. Boiko, J.A. Fedotova, J.V. Kasiuk. J. Alloys Compd. 650, 262 (2015).

[7] Я.А. Ляшенко, А.Н. Заскока. ЖТФ 85, 7, 69 (2015).

[8] S.N. Danilchenko, A.V. Koropov, I.Y. Protsenko, B. SulkioCleff, L.F. Sukhodub. Cryst. Res. Technol. 41, 268 (2006).

[9] T.N. Kołtunowicz, P. Zhukowski, V. Bondariev, J.A. Fedotova, A.K. Fedotov. Acta Phys. Pol. A 123, 932 (2013).

[10] В.М. Береснев, О.В. Соболь, А.Д. Погребняк, П.В. Турбин, С.В. Литовченко. ЖТФ 80, 6, 117 (2010). 
[11] M.K. Samani, X.Z. Ding, N. Khosravian, B. Amin-Ahmadi, Y. Yi, G. Chen, E.C. Neyts, A. Bogaerts, B.K. Tay. Thin Solid Films 578, 133 (2015).

[12] Z.H. Xie, M. Hoffman, P. Munroe, R. Singh, A. Bendavid, P.J. Martin. J. Mater. Res. 22, 2312 (2007).

[13] J. Lackner, L. Major, M. Kot. Bull. Pol. Acad. Sci.: Tech. Sci. 59, 343 (2011).

[14] A.D. Pogrebnjak, S. Bratushka, V.I. Boyko, I.V. Shamanin, Y.V. Tsvintarnaya. Nucl. Instrum. Meth. Phys. Res. B 145, 373 (1998).

[15] A. Gilewicz, B. Warcholinski. Tribol. Int. 80, 34 (2014).

[16] R.A. Koshy, M.E. Graham, L.D. Marks. Surf. Coat. Technol. 202, 1123 (2007).

[17] V. Ivashchenko, S. Veprek, A. Pogrebnjak, B. Postolnyi. Sci. Technol. Adv. Mater. 15, 25007 (2014).

[18] A. Komarov, F. Komarov, P. Żukowski, C. Karwat, A. Kamarou. Vacuum 63, 495 (2001).

[19] А.Д. Погребняк, О.М. Ивасишин, В.М. Береснев. Успехи физики металлов 17, 1 (2016).

[20] A.D. Pogrebnjak, D. Eyidi, G. Abadias, O.V. Bondar, V.M. Beresnev, O.V. Sobol. Int. J. Refract. Met. Hard Mater. 48, 222 (2015)

[21] Л.С. Метлов, М.М. Мышляев, А.В. Хоменко, Я.А. Ляшенко. Письма в ЖТФ 38, 21, 28 (2012).

[22] S. Veprek, M.G.J. Veprek-Heijman, P. Karvankova, J. Prochazka. Thin Solid Films 476, 1 (2005).

[23] A.D. Pogrebnjak, G. Abadias, O.V. Bondar, B.O. Postolnyi, M.O. Lisovenko, O.V. Kyrychenko, A.A. Andreev, V.M. Beresnev, D.A. Kolesnikov, M. Opielak. Acta Phys. Pol. A 125, 1280 (2014). 